\section{Ultrasound evidence of sexual difference in fetal size in first trimester}

Boys born at term weigh on average 50-150 g more than girls and are $0 \cdot 5-1.0 \mathrm{~cm}$ longer. ${ }^{12}$ At 1 year of age these differences have increased to $0.5 \mathrm{~kg}$ and $1-2 \mathrm{~cm} .{ }^{1}$ Conversely, among babies born prematurely a weight difference between the two sexes can be detected only in the last eight to 12 weeks before term. ${ }^{2}$ These observations have led to the assumption that the sexual difference in weight and size is hormone dependent. In order to establish local normal tables of fetal growth a series of normal pregnancies were studied by ultrasonic scanning. Quite unexpectedly, male fetuses were already on average larger than female ones at the first measurement in the 8 th to 12 th week. Therefore a genetic rather than a hormonal mechanism is probably behind the sexual difference in fetal size.

\section{Subjects, methods, and results}

The subjects studied were 101 healthy pregnant women with a reliable history of regular menstrual periods at 28-30 days' interval. Fetal age was calculated from the first day of the last period, knowing that fertilisation occurs two weeks later. In weeks 7 to 13 the fetal crown-rump length was measured two to four times at biweekly intervals. ${ }^{3}$ From week 12 until term the transverse dimension of the fetal head, the biparietal diameter, was determined every four weeks. ${ }^{4}$ The ultrasound scanner was a Nuclear Enterprises Diasonograph NE 4102.

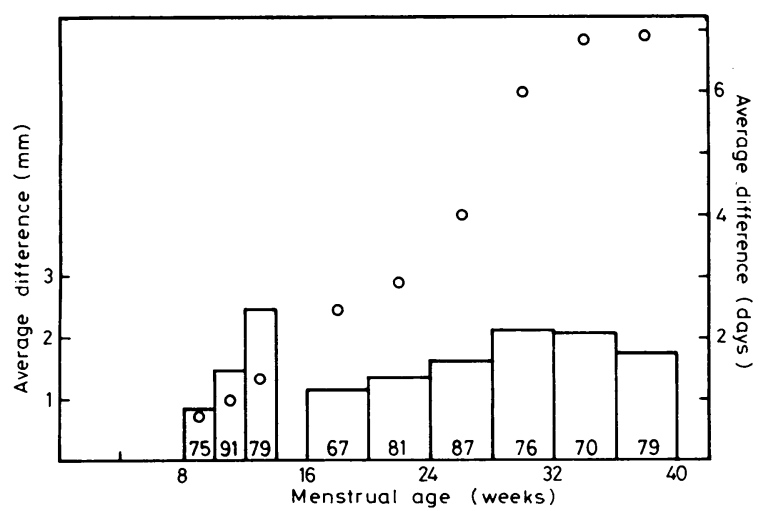

Difference between male and female fetus size during pregnancy $(\mathrm{O}=$ difference in days).

The columns in the figure show the average of the difference between measurements in male and female fetuses for each day during two-week periods (crown-rump length) and four-week periods (biparietal diameter). The number of observations in each period is given at the bottom of the columns. For each period the absolute difference was divided by the corresponding female growth velocity to express the difference in days. Analysis of the results showed that the fetuses tended to stay within tramlines. The growth curves of crown-rump length and biparietal diameter could be described by two square functions where the individual growth curves had a common curvature and almost identical slope but different level. The levels of crown-rump length and biparietal diameter were on average $2.0 \mathrm{~mm}$ $(p<0.01)$ and $1.4 \mathrm{~mm}(\mathrm{p}<0.005)$ higher in male fetuses than in female ones. Also, a simple sign test applied to the average values of crown-rump length and biparietal diameter for each day in the periods weeks 8 to 13 and 12 to 40 , respectively, showed male fetuses significantly bigger than female ones ( $\mathrm{p}<0.05$ and $\mathrm{p}<0.01$ ).

There were 52 girls and 49 boys in the series. The average birth weight of the boys was $40 \mathrm{~g}$ higher than that of the girls and they were $4 \mathrm{~mm}$ longer which is less than the reported differences ${ }^{12}$ but not significantly so. The picture might have been even clearer if the sample had had the usual birthweight difference. There was no correlation between the mothers' height and fetal measurements of crown-rump length and biparietal diameter. This might be expected, since fetal weight is positively correlated to maternal height.

\section{Comment}

In a series of 9846 measurements of biparietal diameter made from the 20 th week till term Persson et $\mathrm{al}^{5}$ found the diameter in male fetuses to be on average $1.7 \%$ larger than in female fetuses. Roughly estimated, this must equal an average difference of $1.2 \mathrm{~mm}$. Tables of fetal weight in weeks 28 to 40 , based on birthweight data, show a small sexual difference at about the 28 th week. ${ }^{2}$ This increases towards term, and it has been generally assumed that the growth difference is hormone dependent.

The columns in the figure show the difference between male and female fetal size in two-week periods for crown-rump length and in four-week periods for biparietal diameter. To enable the differences in crown-rump length and biparietal diameter to be compared these are also expressed by the time necessary for female fetuses to reach male size. Expressed in this way the sex difference in fetal size apparently increases with fetal age, from approximately 1 day at 8 to 12 weeks of gestation to 6 to 7 days at term. Interpolation suggests an intercept with the time-axis to within a distance of a few weeks from the time of conception. Perhaps, therefore, the slightly lower growth rate of the female fetus is already encoded at conception-that is, it is determined by the sex chromosomes.

This work was supported by the Danish Medical Research Council (552-655).

${ }^{1}$ Hammill PVV, Drizd TA, Johnson CL, Reed RB, Roche AF. NCHS growth charts. Monthly Vital Statistics Report 1976;25(3):1-22.

2 Thomson AM, Billewicz WZ, Hytten FE. The assessment of fetal growth. fournal of Obstetrics and Gynaecology of the British Commonwealth 1968;75:903-16.

${ }^{3}$ Robinson HP. Sonar measurement of fetal crown-rump length as means of assessing maturity in first trimester of pregnancy. $\mathrm{Br} \mathrm{Med} \mathcal{F} 1973$;iv: 28-31.

4 Campbell S. An improved method of fetal cephalometry by ultrasound. Fournal of Obstetrics and Gynaecology of the British Commonwealth 1968; 75:568-76.

5 Persson PH, Grennert L, Gennser G. Impact of fetal and maternal factors on the normal growth of the biparietal diameter. Acta Obstet Gynecol Scand [Suppl] 1978;78:21-7.

(Accepted 2 September 1980)

Ultrasound Laboratory, Department of Obstetrics and Gynaecology

YB, Rigshospitalet, Copenhagen

JAN FOG PEDERSEN, MD, research associate (present address: Ultrasound Laboratory, Glostrup University Hospital, DK 2600 Glostrup, Denmark)

\section{Outbreak of respiratory syncytial virus infection in the elderly}

Respiratory syncytial virus mainly affects young children, with only about $2 \%$ of cases reported to the Communicable Diseases Surveillance Centre in the over-60 age group. ${ }^{1}$ We describe an outbreak in a psychogeriatric hostel.

\section{Patients, methods, and results}

Out of 40 residents aged $69-90$ years, 17 suddenly developed fever, anorexia, and a non-productive cough. Findings in the chest ranged from a few basal crepitations to widespread rales and rhonchi. Most patients recovered rapidly in three to four days, but the first to become ill, an 81year-old woman, developed a severe chest infection with left ventricular failure, deteriorated gradually, and died a month later. Six patients became ill about two weeks after the first case, eight a further five to eight days later, and two after a further five days. All were given antibiotics, usually amoxycillin or erythromycin.

Paired sera from two cases showed a rise in respiratory syncytial virus complement fixation titres (expressed as a reciprocal dilution) from less than 20 to 160 . Convalescent sera from the other patients showed titres of 320 in three, 160 in eight, 80 in two, and 40 in two. Three residents who had not been ill were found to have titres of 20 in one case and 40 in the other two, and two members of staff who had been ill (one at the time of the index case) had titres of 80. Complement fixation titres to a wide range of other viruses, including influenza A and B and parainfluenza 3, were examined without any positive findings other than some mildly raised values to influenza $A$ or $B$, or both, doubtless due to prophylactic immunisation three months before the outbreak described.

\section{Comment}

Respiratory syncytial virus is a common cause of infection in children. Research in the United States has shown that in older 